\title{
Detección del Polimorfismo en el Gen del Receptor de Melatonina (MT1) en la Oveja Criolla Araucana
}

\author{
Detection of MT1 Melatonin Receptor Gene Polymorphism (MT1) in the Araucana Creole Sheep \\ "Quiñones. J; **Bavo. S; *Paz. E \& ***Sepúlveda, N.
}

QUIÑONES, J.; BRAVO. S.; PAZ, E. \& SEPÚLVEDA, N. Detección del polimorfismo en el gen del receptor de melatonina (MT1) en la oveja criolla araucana. Int. J. Morphol., 30(2):546-549, 2012.

RESUMEN: La melatonina es una hormona que regula los ciclos circadianos y muchos de los aspectos reproductivos de los mamíferos y es secretada por la glándula pineal en las horas de ausencia de luz. Esta hormona posee receptores de alta afinidad acoplados a proteínas de tipo G, denominados MT1. Un polimorfismo de la secuencia que codifica para estos receptores estaría involucrado en el control de la reproducción estacional de los ovinos. El propósito de este estudio busca determinar la presencia del polimorfismo del receptor MT1 en la oveja criolla Araucana, un ovino local en el que se ha registrado un corto anestro reproductivo. Para poder realizar este trabajo se utilizó la técnica denominada reacción en cadena de la polimerasa para polimorfismo en el tamaño de los fragmentos de restricción PCR-RFLP, para lo cual, se obtuvieron muestras de ADN genómico de 50 ovejas Araucanas, las cuales fueron digeridas con la endonucleasa de restricción Mnl1. Se logró identificar la presencia del polimorfismo del receptor MT1 en la oveja Araucana. Los genotipos se hallaron en una frecuencia de $68 \%$ para el genotipo $+/+, 28 \%$ para el genotipo $+/-$ y4\% para el genotipo -/-. Este alto porcentaje de animales con genotipo +/+ podría explicar el corto anestro reproductivo que presenta esta raza.

PALABRAS CLAVES: Reproducción ovina; Anestro; Marcadores moleculares.

\section{INTRODUCCIÓN}

La melatonina es una hormona secretada por la glándula pineal en ausencia de luz, esta información es percibida por la retina la cual es conducida a través de los nervios ópticos y el tracto retinohipotalámico, la señal llega a la parte posterior del cerebro, específicamente al ganglio cervical superior (Arendt, 1998). Este órgano supone la transición entre una señal física y una señal química. En el ganglio cervical superior se libera noradrenalina, la cual es captada por receptores alfa y beta adrenérgicos de la membrana celular de los pinealocitos que a su vez son los responsables de la síntesis de n-acetil transferasa, una enzima fundamental en la síntesis de melatonina a través de aminoácido triptófano (Arroyo, 2011). Se le han atribuido numerosas funciones relacionadas como agente regulador de los ciclos circadianos, funciones inmunológicas, inhibición de tumores y últimamente como un antioxidante (Reiter, 2003; Turek \& Gillette, 2004). En ovinos, la melatonina tiene un efecto importante sobre el comportamiento reproductivo, estaría asociado a la fertilidad
(Abecia et al., 2007) y a la duración del anestro reproductivo en esta especie (Nicolo et al., 2008). Existen receptores de alta afinidad para la melatonina acoplados a proteínas tipo $\mathrm{G}$ llamados MT1 que regulan su efecto sobre los tejidos que tienen relación con las características reproductivas (Dubocovich et al., 2010). El gen que codifica el receptor MT1 es polimórfico en individuos de una misma raza (Messer et al., 1997; Carcangiu et al., 2009). Existen trabajos donde se ha establecido una asociación entre el polimorfismo del receptor MT1 y el desarrollo reproductivo asociado a la duración del anestro en algunas razas ovinas (Chu et al., 2003; Mateescu et al., 2009). Estas características han sido reportadas principalmente en ovinos de razas criollas, más rústicas y que viven en condiciones climáticas complejas.

En el sur de Chile, existe la oveja criolla Araucana, un ovino local que recientemente se ha caracterizado en su aspecto morfoestructural y productivo (Bravo \& Sepúlveda,

\footnotetext{
* Licenciado en Biotecnología. Universidad de La Frontera, Temuco, Chile.

** Programa de Doctorado en ciencias mención Biología Celular y Molecular Aplicada. Facultad de Ciencias Agropecuarias y Forestales. Universidad de La Frontera, Temuco, Chile.

${ }^{* * *}$ Departamento de Producción Agropecuaria. Facultad de Ciencias Agropecuarias y Forestales. Universidad de La Frontera, Temuco, Chile. Este estudio fue realizado con aportes del Proyecto DIUFRO N ${ }^{\circ}$ : ED10-0039, Universidad de La Frontera, Temuco, Chile.
} 
2010). Es utilizado como un animal de doble propósito (carne y lana), está adaptado a las condiciones climáticas locales y es criada principalmente por pequeños agricultores de la región (Sepúlveda, 1999). Estos animales presentan un corto anestro reproductivo comparado con otras razas existentes en la región de la Araucanía, característica reproductiva muy valorada por los agricultores (Sepúlveda et al., 2001). El objetivo de este de este trabajo fue identificar la presencia del polimorfismo A612G del receptor MT1 y establecer las frecuencias genotípicas de las variantes de este polimorfismo en ovejas de la raza Araucana.

\section{MATERIAL Y MÉTODO}

Manejo animal y muestreo. Se utilizaron 50 ovejas de la raza criolla Araucana pertenecientes al Núcleo Genético de ovinos Araucanos del Campo Experimental Maquehue de la Universidad de La Frontera (38 50'29" latitud sur y $72^{\circ} 41^{\prime} 27^{\prime \prime}$ longitud oeste), ubicado en la comuna de Freire a $14 \mathrm{Km}$ de la comuna de Padre Las Casas, región de La Araucanía, Chile.

A cada hembra se le extrajo $6 \mathrm{ml}$ de sangre mediante punción de la vena yugular usando el sistema de extracción BD Vacutainer ${ }^{\circledR}$ K2 EDTA 10,8 mg (BD, Franklin Lakes, NJ, EUA). Las muestras de sangre fueron trasladadas a $4^{\circ} \mathrm{C}$ al laboratorio de Producción Animal de la Universidad de La Frontera donde se extrajo el ADN genómico de cada animal, utilizando el kit comercial Axyprep Blood Genomic DNA Miniprep Kit (AxigenSci. Inc., CA, EUA), el cual fue almacenado a $-20^{\circ} \mathrm{C}$ hasta su posterior uso.

Genotipificación y reacción en cadena de la polimerasa para polimorfismo en el tamaño de los fragmentos de restricción (PCR-RFLP). Se diseñó un set de partidores por medio del software Amplifx versión 1.5, basados en la secuencia del exón II del gen que codifica el receptor MT1 (código de acceso Genbank: U14109) del Centro Internacional de Información sobre Biotecnología (NCBI, EUA). Forward: 5'-GGCGCTGGCGTCTATAGTTAACAA-3' y reverse: 5'-GATCGCATTGAGGCAGCTGTTGAA-3'.

El set de partidores amplificó una región del exón II de gen que codifica para el receptor MT1 de $631 \mathrm{pb}$. La PCR se realizó en tubos de $0,2 \mathrm{ml}$ en un termociclador MultigeneGradient (Labnet International Inc. NJ, EUA). El ciclo térmico de amplificación incluyo una denaturación inicial de $94^{\circ} \mathrm{C}$ por 5 minutos, seguido de 35 ciclos de denaturación a $94^{\circ} \mathrm{C}$ por 1 minuto, hibridación a $62,8^{\circ} \mathrm{C}$, extensión $72^{\circ} \mathrm{C}$ por 1 minuto, y una extensión final de $72^{\circ} \mathrm{C}$ por 10 minutos. Los productos de PCR fueron chequeados en un gel de agarosa al 1,5\% teñido con GelRedTM (Biotium, Inc. EUA).

Se procedió a elaborar un mapa de restricción para la endonucleasa Mnl1 (New EnglandBiolabs. Inc. EUA) según lo descrito por Messer et al. Para la digestión del producto de PCR se utilizó $3 \mathrm{U}$ de la endonucleasa de restricción Mnl1 (New England Biolabs. Inc. EUA) y se incubó por 3 horas a $37^{\circ} \mathrm{C}$.Una vez finalizada la digestión se identificaron los diferentes alelos del polimorfismo A612G (+/+, +/- y -/-) en geles de agarosa al 3\%, teñido con GelRedTM (Biotium, Inc. EUA).

Análisis estadístico. Se utilizó el software Genepop online versión 4.0.10 para determinar la frecuencia alélicas y genotípicasdel polimorfismo $\mathrm{A} 612 \mathrm{G}$ en la muestra de ovejas evaluadas.

\section{RESULTADOS Y DISCUSIÓN}

Por PCR se amplificó una región de 631 pb que corresponden al exón II del receptor MT1 de la melatonina en ovinos. La digestión con la endonucleasa Mnllpermitio identificar el polimorfismo en la posición 612 (Fig.1) donde existe una sustitución de $\mathrm{G}$ por A generando los genotipos +/+, +/- y -/- (Tabla I).

Tabla I. Frecuencia alélica y genotípica del polimorfismo A612G en ovejas criollas Araucanas $(n=50)$.

\begin{tabular}{ccccc}
\hline \multicolumn{2}{c}{ Frecuencia alélica } & \multicolumn{3}{c}{ Frecuencia genotípica } \\
\hline+ & - & $+/+$ & $+/-$ & $-/-$ \\
0,82 & 0,18 & $68 \%$ & $28 \%$ & $4 \%$ \\
\hline
\end{tabular}

El análisis con el software Genepop arrojó una frecuencia genotípica observada de $68 \%$ para el genotipo $+/+$, $28 \%$ para el genotipo $+/$ - y4\% para el genotipo -/- (Tabla I), valores son muy similares a los obtenidos en otros trabajos (Carcangiu et al., 2009), observándose diferencias significativas en las frecuencias obtenidas en los genotipos $+/+$ y /- en ovejas Araucanas.

El primer genotipo presente en la figura $1(+/+)$ mostró 4 fragmentos: 236, 158, 82 y 67 pb. Este genotipo, según la literatura sería la variante de interés y presenta todos los sitios de reconocimiento de la enzima Mnl1 (Mateescu et al.). La frecuencia del genotipo $+/+$ (Tabla I) presente en este estudio fue similar a la encontrada en ovejas Sarda (68\%) (Carcangiu et al., 2011), sin embargo es más alto que el encontrado en razas ovinas francesas $(52,4 \%)$ según lo descrito por Pelletier et al. (2000). 
1

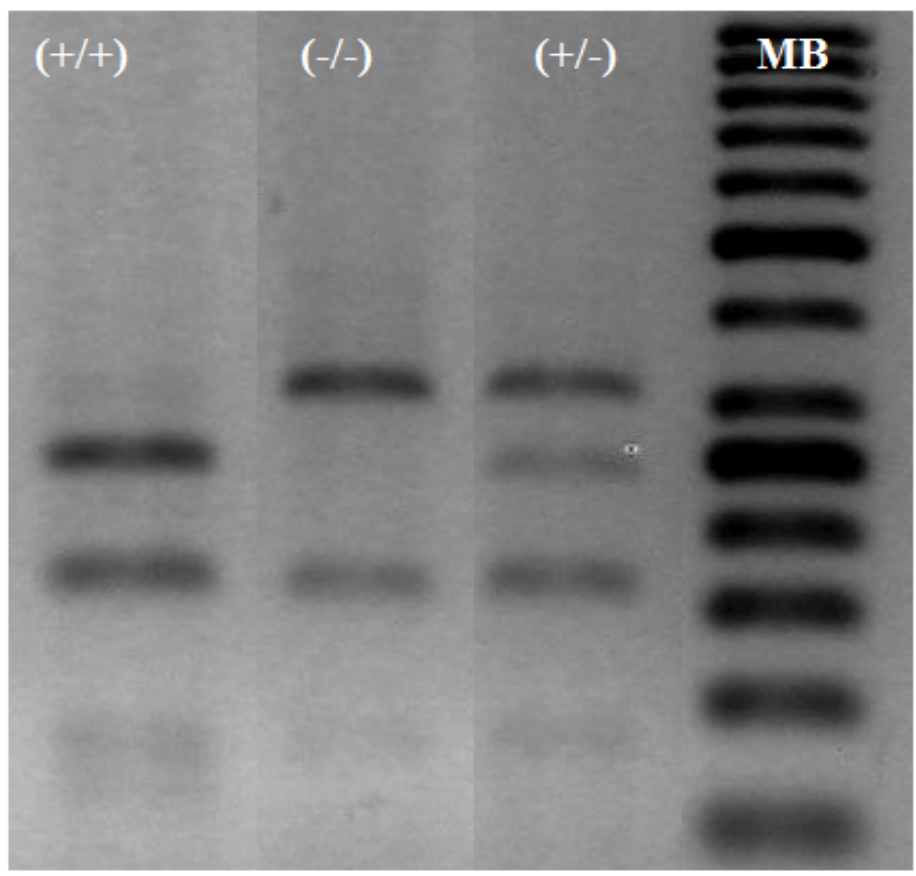

300

250

200

150

100

Fig. 1. PCR-RFLP del exón II del receptor MT1 de la melatonina en ovejas crio1las Araucanas. Línea 1: genotipo +/+, línea 2 genotipo -/-, línea 3 genotipo +/- y línea 4 marcador de peso molecular de $50 \mathrm{pb}$.

El segundo genotipo (-/-) presente en la Figura 1 presentó 3 fragmentos: 303, 158 y 82 pb. Este genotipo -/-, se produce por una sustitución de G por A. Pelletier et al. reportan que este cambio de base elimina el sitio de reconocimiento de la enzima Mnl1 e impide que corte esa porción de la secuencia. Además, encontró una asociación entre el genotipo -/- y la actividad anovulatoria en la raza Merino.

El tercer genotipo (+/-) presente en la Figura 1 corresponde a los individuos heterocigotos los alelos de ambas variantes y que posee todos los fragmentos en discusión: 303, 236, 158, 82 y 67 pb.

Hernández et al. (2005) no encontró ninguna asociación entre el polimorfismo del receptor MT1 y la estacionalidad reproductiva en ovinos, sin embargo este resultado parece ser muy particular y característico de la raza Île-de-France, raza ovina del tronco Merino y de baja estacionalidad. Por el contrario Mateescu et al. encontró diferencias significativas entre los portadores del alelo + con respecto al alelo -, ya que estos individuos necesitarían solo 124 días entre el primer y segundo parto en la raza Dorset.

La frecuencia del alelo + identificado en ovejas Araucanas (Tabla I), fue mayor a las reportadas en las razas ovinas Cornell Dorset, Tisdale's, Polypay, Hampshire y Han (Notter \& Cockett, 2005). Además algunos autores han descrito el alelo + como el responsable de un corto anestro en ovejas (Notter \& Cockett; Chu et al., 2006).

De acuerdo a los resultados obtenidos en este estudio, la alta presencia del alelo + sería el responsable del corto anestro reproductivo que presenta este ovino criollo. Pudiéndose iniciar un proceso de selección de los animales que presenten este alelo y contribuir con la caracterización de la raza, sin olvidar que la reproducción ovina también es regulada por factores como el efecto macho o la disponibilidad de alimentos (Ptaszynska \& Molina, 2007).

De los antecedentes obtenidos podemos concluir que la población de ovejas Araucanas evaluadas presentó el polimorfismo A612G del receptor MT1 de melatonina, con una alta presencia del genotipo que se relaciona a un corto anestro reproductivo. Este polimorfismo podría servir como un marcador molecular para la selección de animales de corto anestro, característica que determina la estacionalidad reproductiva en razas ovinas.

QUIÑONES, J.; BRAVO. S.; PAZ, E. \& SEPÚLVEDA, N. Detection of MT1 melatonin receptor gene polymorphism (MT1) in the araucana creole sheep. Int. J. Morphol., 30(2):546-549, 2012.

SUMMARY: Melatonin is a hormone that regulates circadian rhythms and many of the reproductive aspects of mammals and is secreted by the pineal gland during the hours of absence of light. This hormone has high affinity receptors coupled to G-like proteins, termed MT1. A polymorphism of the sequence coding for these receptors was involved in the control of seasonal reproduction in sheep. The purpose of this study was to determine the presence of MT1 receptor polymorphism in Araucana creole sheep, a local breed with a short reproductive anestrus. To carry out this work, we used a technique called polymerase chain reaction-restriction fragment lengh polymorphism PCR-RFLP, for which samples were obtained from genomic DNA of 50 Araucana sheep, which were digested with Mnl1 restriction endonuclease. It was possible to identify the presence of MT1 receptor polymorphism in Araucana sheep. The genotypes were found in a genotype frequency of $68 \%$ for genotype $+/+, 28 \%$ for genotype $+/-\mathrm{y} 4 \%$ for genotype $-/$ - . This high percentage of animals with genotype $+/+$ could explain the short reproductive anestrus featuring this breed.

KEY WORDS: Sheep reproduction; Seasonal reproduction; Molecular markers. 


\section{REFERENCIAS BIBLIOGRÁFICAS.}

Abecia, J.; Valares, J.; Forcada, F.; Palacín, I.; Martín, S. \& Martino, A. The effect of melatonin on the reproductive performance of three sheep breeds in Spain. Small Rum. Res., 69:10-6, 2007.

Arendt, J. Melatonin and the pineal gland: influence on mammalian seasonal and circadian physiology. Rev. Reprod., 3:13-22, 1998.

Arroyo, J. Estacionalidad reproductiva de la oveja en México. Trop. Subtrop. Agroecosyt., 14:829-45, 2011.

Bravo, S. \& Sepúlveda, N. Índices zoométricos en ovejas Criollas Araucanas. Int. J. Morphol., 28:489-95, 2010.

Carcangiu, V.; Mura, M.; Vacca, M.; Pazzola, M.; Dettori, M.; Luridiana, S. \& Bini, P. Polymorphism of the melatonin receptor MT1 gene and its relationship with seasonal reproductive activity in the Sarda sheep breed. Anim. Reprod. Sci., 116:65-72, 2009.

Carcangiu, V.; Sebastiano, L.; Vacca, G.; Daga, C. \& Mura, M. A polymorphism at the melatonin receptor 1A (MTNR1A) gene in Sarda ewes affects fertility after A.I. in the spring. Reprod. Fertil. Dev., 23:376-80, 2011.

Chu, X.; Ji1, C. \& Chen, G. Association between PCR-RFLP of melatonin receptor 1a gene and high prolificacy in small Tail Han sheep. Asian-Austr. J. Anim. Sci., 16:1701-4, 2003.

Chu, X.; Cheng, D.; Liu, W.; Fang, L. \& Ye, S. Association between melatonin receptor $1 \mathrm{~A}$ gene and expression of reproductive reproductive seasonality in sheep. Asian-Austr. J. Anim. Sci., 19:1079-84, 2006.

Dubocovich, M.; Delagrange, P.; Krause, D.; Sugden, D.; Cardinali, D. \& Olcese, J. Classification, and pharmacology of G proteincoupled melatonin receptors. Pharmacol. Rev., 62:343-80, 2010.

Hernandez, X.; Bodin, L.; Chesneau, D.; Guillaume, D.; Chemineaua, P.; Malpaux, B. \& Migaud, M. Relationship between MT1 melatonin receptor gene polymorphism and seasonal physiological responses in Île-de-France ewes. Reprod. Nutr. Dev., 45:151-62, 2005.

Mateescu, R.; Lunsford, A. \& Thonney, M. Association between melatonin receptor $1 \mathrm{~A}$ gene polymorphism and reproductive performance in Dorset ewes. J. Anim. Sci., 87:2485-28, 2009.

Messer, L.; Wang, L.; Tuggle, C.; Yerle, M.; Chardon, P.; Pomp, P.; Womack, J.; Barendse, W.; Crawford, A.; Notter, D. \& Rothschild, M. Mapping of the melatonin receptor la (MTNR1A) gene in pigs, sheep, and cattle. Mamm. Genome., 8: 368-70, 1997.
Nicolo, G.; Morris, S.; Kenyon, P.; Morel, P. \& Parkinson, T. Melatonin-improved reproductive performance in sheep bred out of season. Anim. Reprod. Sci., 109:124-33, 2008.

Notter, D. \& Cockett; N. Opportunities for detection and use of QTL influencing seasonal reproduction in sheep: a review. Genet. Sel. Evol., 37:39 -53, 2005.

Pelletier, J.; Bodin, L.; Hanocq, E.; Malpaux, B.; Teyssier, J.; Thimonier, J. \& Chemineau, P. Association between expression of reproductive seasonality and alleles of the gene for Mel1a receptor in the ewe. Biol. Reprod., 62:1096-101, 2000.

Ptaszynska, M. \& Molina, J. Compendio de la reproducción animal. 9. ed. Editorial Sinervia, Uruguay, 2007.

Reiter, R. Melatonin: clinical relevance. Best. Pract. Res. Clin. Endocrinol. Metabol., 17: 273-85, 2003.

Sepúlveda, N. Características productivas de los rebaños de ganaderos indígenas mapuches en la IX región de Chile. El Arca, 3:47-52, 1999.

Sepúlveda, N.; Neculmán, R.; Herrera, M. \& Rodero, E. Parámetros de fertilidad natural en ovejas de la agrupación araucana. XXVI Jornadas Científicas y V Internacionales de la Sociedad Española de Ovinotecnia y Caprinotecnia (SEOC), Sevilla (España). Producción ovina y caprina, 26:962-6, 2001.

Turek, F \& Gillette, M. Melatonin, sleep, and circadian rhythms: rationale for development of specific melatonin agonists. Sleep Med., 5:523-32, 2004.

Dirección para correspondencia:

Prof. Dr. Néstor Sepúlveda

Departamento de Producción Agropecuaria

Facultad de Ciencias Agropecuarias y Forestales

P. O. Box 54-D.

Universidad de La Frontera

Temuco - CHILE

Email: nestor@ufro.cl

Recibido : 22-12-2011

Aceptado: 26-02-2012 